\title{
Functional Coupling between Sulfonylurea Receptor Type 1 and a Nonselective Cation Channel in Reactive Astrocytes from Adult Rat Brain
}

\author{
Mingkui Chen, ${ }^{1}$ Yafeng Dong, ${ }^{1}$ and J. Marc Simard ${ }^{1,2,3}$ \\ Departments of ${ }^{1}$ Neurosurgery, ${ }^{2}$ Pathology, and ${ }^{3}$ Physiology, University of Maryland at Baltimore, Baltimore, Maryland 21201
}

\begin{abstract}
We previously identified a novel, nonselective cation channel in native reactive (type R1) astrocytes (NR1As) from injured rat brain that is regulated by cytoplasmic $\mathrm{Ca}^{2+}$ and ATP $\left(\mathrm{NC}_{\mathrm{Ca}-\mathrm{ATP}}\right)$ and exhibits sensitivity to block by adenine nucleotides similar to that of sulfonylurea receptor type 1 (SUR1). Here we show that SUR1 is involved in regulation of this channel. NR1As within the site of injury and after isolation exhibited specific binding of FITC-tagged glibenclamide and were immunolabeled with anti-SUR1 antibody, but not with anti-SUR2, anti-Kir6.1 or anti-Kir6.2 antibodies, indicating absence of ATP-sensitive $\mathrm{K}^{+}\left(\mathrm{K}_{\mathrm{ATP}}\right)$ channels. RT-PCR confirmed transcription of mRNA for SUR1 but not SUR2. Several properties previously associated exclusively with SUR1-regulated $\mathrm{K}_{\mathrm{ATP}}$ channels were observed in patch-clamp experiments using $\mathrm{Cs}^{+}$as the charge carrier: (1) the sulfonylureas, glibenclamide and tolbutamide, inhibited $\mathrm{NC}_{\text {Ca-ATP }}$ channels with $\mathrm{EC}_{50}$ values of $48 \mathrm{nM}$ and $16.1 \mu \mathrm{M}$, respectively; (2) inhibition by sulfonylureas was lost after exposure of the intracellular face to trypsin or anti-SUR1 antibody; (3) channel inhibition was caused by a change in kinetics of channel closing, with no change in channel amplitude or open-channel dwell times; and (4) the SUR activator (" $\mathrm{K}_{\mathrm{ATP}}$ channel opener"), diazoxide, activated the $\mathrm{NC}_{\text {Ca-ATP }}$ channel, whereas pinacidil and cromakalin did not. Also, glibenclamide prevented cell blebbing after ATP depletion, whereas blebbing was produced by exposure to diazoxide. Our data indicate that SUR1 is functionally coupled to the pore-forming portion of the $\mathrm{NC}_{\text {Ca-ATP }}$ channel, providing the first demonstration of promiscuity of SUR1 outside of the $\mathrm{K}^{+}$inward rectifier family of channels.
\end{abstract}

Key words: sulfonylurea; SUR1; glibenclamide; diazoxide; cation channel; cell swelling; astrocyte; brain injury; patch clamp

\section{Introduction}

The antidiabetic sulfonylureas, which inhibit ATP-sensitive $\mathrm{K}^{+}$ $\left(\mathrm{K}_{\mathrm{ATP}}\right)$ channels in pancreatic $\beta$ cells and stimulate insulin release in diabetes mellitus, mediate their effect on $\mathrm{K}_{\mathrm{ATP}}$ channels via a high-affinity sulfonylurea receptor (SUR) (Panten et al., 1989; Aguilar-Bryan et al., 1995). Several isoforms of SUR, termed SUR1, SUR2A, SUR2B, and SUR2C, have been identified and cloned (Aguilar-Bryan et al., 1995; Inagaki et al., 1996; Isomoto et al., 1996; Lawson, 2000). These receptors belong to the ATPbinding cassette $(\mathrm{ABC})$ transporter family, of which the cystic fibrosis transmembrane conductance regulator (CFTR), another ion channel modulator, is also a member (Higgins, 1992; AguilarBryan et al., 1995).

$\mathrm{K}_{\mathrm{ATP}}$ channels are heteromultimers, with Kir6.x forming the conductive pores and SURx functioning as regulatory subunits (Shyng et al., 1997a; Tucker et al., 1997, 1998; Babenko et al., 1998; Drain et al., 1998). SUR imparts sensitivity to antidiabetic sulfonylureas such as glibenclamide and tolbutamide and is responsible for activation by a chemically diverse group of agents termed " $\mathrm{K}^{+}$channel openers" (here termed "SUR activators")

Received July 1, 2003; revised July 1, 2003; accepted July 21, 2003.

This work was supported by a Merit Review Grant from the Veterans Administration (Baltimore Veterans Administration, Baltimore, MD). We thank Dr. Jia Bi Yang for expert technical assistance.

Correspondence should be addressed to Dr. J. Marc Simard, Department of Neurosurgery, 22 South Greene Street, Suite 12SD, Baltimore, MD 21201-1595. E-mail: msimard@surgery1.umaryland.edu.

Copyright $\odot 2003$ Society for Neuroscience $\quad 0270-6474 / 03 / 238568-10 \$ 15.00 / 0$ such as diazoxide, pinacidil, and cromakalin (Aguilar-Bryan et al., 1995; Inagaki et al., 1996; Isomoto et al., 1996; Nichols et al., 1996; Shyng et al., 1997b). In various tissues, molecularly distinct SURs are coupled to distinct channel moieties to form different $\mathrm{K}_{\mathrm{ATP}}$ channels with distinguishable physiological and pharmacological characteristics. The $\mathrm{K}_{\mathrm{ATP}}$ channel in pancreatic $\beta$ cells is formed from SUR1 linked with Kir6.2, whereas the cardiac and smooth muscle $\mathrm{K}_{\text {ATP }}$ channels are formed from SUR2A and SUR2B linked with Kir6.2 and Kir6.1, respectively (Fujita and Kurachi, 2000). In addition to these principal constructs, another inward rectifier channel, Kir1.1a, has been reported to link to another ABC ion channel regulator, CFTR (Ruknudin et al., 1998), or even to SUR itself (Ammala et al., 1996), thereby gaining sensitivity to sulfonylureas. To date, the only channels known to be regulated by SURx are inward rectifier $\mathrm{K}_{\mathrm{ATP}}$ channels formed from Kir6.1, Kir6.2, or possibly Kir1.1a.

We recently identified a novel $\mathrm{Ca}^{2+}$-activated, ATP-sensitive nonselective cation channel $\left(\mathrm{NC}_{\mathrm{Ca}-\mathrm{ATP}}\right)$ in native (not cultured) reactive (type $\mathrm{R} 1$ ) astrocytes (NR1As) from adult rat brain (Chen and Simard, 2001). This channel, which is nearly equally permeable to $\mathrm{K}^{+}, \mathrm{Na}^{+}, \mathrm{Rb}^{+}, \mathrm{Li}^{+}$, and $\mathrm{Cs}^{+}$, is readily distinguished from $\mathrm{K}_{\text {ATP }}$ channels, which are not permeable to $\mathrm{Na}^{+}$and $\mathrm{Cs}^{+}$. The sensitivity of the $\mathrm{NC}_{\mathrm{Ca}-\mathrm{ATP}}$ channel to ATP suggested that it might belong to the $\mathrm{ABC}$ transporter family, prompting us to hypothesize that sulfonylureas might modulate it. Here we report that the $\mathrm{NC}_{\mathrm{Ca}-\mathrm{ATP}}$ channel exhibits physiological and pharmaco- 
logical properties previously associated only with $\mathrm{K}_{\mathrm{ATP}}$ channels possessing the SUR1 regulatory subunit, that glibenclamidemediated channel inhibition was prevented by anti-SUR1 antibody, and that blocking the channel with glibenclamide protected cells from blebbing secondary to $\mathrm{Na}$ azide-induced ATP depletion. Together, our data show that SUR1 is expressed, is coupled to, and regulates the pore-forming portion of the $\mathrm{NC}_{\mathrm{Ca}-}$ ATP channel in NR1A and that SUR-mediated regulation of this channel plays a role in blebbing and swelling of reactive astrocytes.

\section{Materials and Methods}

Cell preparations. All animal protocols were approved by the Institutional Animal Care and Use Committee of the University of Maryland. Native reactive astrocytes from adult brain were obtained from the gliotic capsule that forms around gelatin sponges (Gelfoam, Upjohn Co., Kalamazoo, MI) implanted into a stab wound in the parietal lobe of 8-week-old Wistar rats as described previously (Perillan et al., 1999, 2000). Sponge pieces were harvested at $8 \mathrm{~d}$ and washed three times in PBS, pH 7.4. Washed pieces were placed in an Eppendorf tube containing artificial CSF (ACSF) composed of (mM): $124 \mathrm{NaCl}, 5 \mathrm{KCl}, 1.3 \mathrm{MgCl}_{2}, 2 \mathrm{CaCl}_{2}, 26$ $\mathrm{NaHCO}_{3}$, and $10 \mathrm{D}$-glucose, $\mathrm{pH} 7.4, \approx 290 \mathrm{mOsm}$, with $20 \mathrm{U} / \mathrm{ml}$ papain, $10 \mathrm{mg} / \mathrm{ml}$ trypsin inhibitor, and $0.01 \%$ DNase (Worthington, Lakewood, $\mathrm{NJ}$ ). The digestion system was transferred to an incubator (humidified $90 \%$ air $/ 10 \% \mathrm{CO}_{2}, 37^{\circ} \mathrm{C}$ ) for $20 \mathrm{~min}$ and gently triturated every $5 \mathrm{~min}$. The cell suspension was centrifuged at $3000 \mathrm{rpm}$ for $1 \mathrm{~min}$, and pelleted cells were further purified by density gradient centrifugation in Histopaque-1077 (Sigma, St. Louis, MO) to remove red blood cells (RBCs) (Bhat et al., 1990). After this purification process, the population of RBCs was $<1 \%$ of cells when examined by phase-contrast microscopy. Cells were resuspended in ACSF and stored at $4^{\circ} \mathrm{C}$ until studied.

The cell-isolation protocol yielded cells of various sizes, ranging from 11 to $45 \mu \mathrm{m}$ diameter; some were phase bright, and others were phase dark. Most of the cells were large ( $\sim 30 \mu$ m diameter), round, and phase bright and were readily distinguished from other cells using phase-contrast optics. These cells have previously been shown to be uniformly labeled with anti-glial fibrillary acidic protein (GFAP) antibody (Perillan et al., 1999, 2000). We have referred to these reactive astrocytes as type R1 astrocytes, to distinguish them from other subpopulations, including type R2 astrocytes, which are phase dark (Dalton et al., 2003), and stellate astrocytes, which have long processes (more than one cell length) (Perillan et al., 2000). Compared with type R1 astrocytes, both of the other subtypes possess very different electrophysiological characteristics (Perillan et al., 2000), and neither exhibits currents attributable to $\mathrm{NC}_{\mathrm{Ca}-\mathrm{ATP}}$ channels. For the experiments reported here, we studied only freshly isolated, native (not cultured) type $\mathrm{R} 1$ astrocytes, which are the cells that reliably express the $\mathrm{NC}_{\mathrm{Ca}-\mathrm{ATP}}$ channel (Chen and Simard, 2001).

A rat insulinoma cell line, RIN-m5f, obtained from American Type Culture Collection (Manassas, VA), was used as a positive control for $\mathrm{K}_{\mathrm{ATP}}$ channel mRNA (Aguilar-Bryan et al., 1995). Cells were grown in RPMI 1640 medium with 2 mM L-glutamine supplemented with $10 \%$ fetal bovine serum. Cells were maintained in a humidified atmosphere of $5 \% \mathrm{CO}_{2} / 95 \%$ air at $37^{\circ} \mathrm{C}$. Culture medium was exchanged every $3 \mathrm{~d}$.

Imaging. Frozen sections $(8 \mu \mathrm{m})$ of formaldehyde-fixed brains from injured animals were prepared. To assess glibenclamide binding, sections were incubated for $60 \mathrm{~min}$ at room temperature with $20 \mathrm{~nm}$ FITCconjugated glibenclamide (BODIPY-FL-glyburide, Molecular Probes, Eugene, OR), either without or with $1 \mu \mathrm{M}$ unlabeled glibenclamide. Immunolabeling of tissue sections or of isolated cells was performed as described previously (Perillan et al., 1999). Primary antibodies used were directed against GFAP (1:5000; Sigma), SUR1 and SUR2 (1:200; Santa Cruz Biotechnology, Santa Cruz, CA), and Kir6.1 and Kir6.2 (1:200; Santa Cruz Biotechnology). Secondary antibodies used included speciesappropriate Alexa 546-conjugated secondary antibody (1:200 dilution; Molecular Probes) for fluorescence imaging. Cell nuclei were labeled using 4,6-diamidino-2-phenylindole (DAPI) (Sigma). Alternatively, when capturing low-power views of tissue sections, we used speciesappropriate horseradish peroxidase-conjugated secondary antibodies.
Specimens were examined using a Nikon Eclipse E1000 microscope. Images were captured using a SenSys digital camera (Roper Scientific) and processed using a personal computer running IPLab software (version 3.0, Scanalytics). Post-processing of images was performed using Adobe Photoshop (version 5.0, Adobe Systems).

Total RNA isolation and RT-PCR. We used insulinoma RIN-m5f cell and rat cardiomyocytes as positive controls for SUR1 and SUR2, respectively. Total RNA was isolated from cells and tissues using RNeasy Mini Kit (Qiagen, Valencia, CA) following the manufacturer's protocol. Cardiac tissue was first treated with proteinase $\mathrm{K}$ before RNA isolation was performed. RT-PCR was performed using the Titanium One-Step RTPCR kit (BD Biosciences Clontech, Palo Alto, CA). The target transcript was reverse transcribed at $50^{\circ} \mathrm{C}$ for $1 \mathrm{hr}$ and amplified using 35 cycles under the following conditions: $94^{\circ} \mathrm{C}, 30 \mathrm{sec} ; 65^{\circ} \mathrm{C}, 30 \mathrm{sec} ; 68^{\circ} \mathrm{C}, 1 \mathrm{~min}$. The oligonucleotide primers corresponding to SUR1 and SUR2 were as follows: SUR1 (GenBank accession number L40624), forward primer (base 4774-4792) TGAAGCAACTGCCTCCATC, reverse primer (base 4955-4937) GAAGCTTTTCCGGCTTGTC; SUR2 (accession number D83598), forward primer (base 4853-4872) ACCTGCTCCAGCACAAGAAT, reverse primer (base 4997-4976) TCTCTTCATCACAATGACCAGG. RT-PCR products were analyzed using $2.5 \%$ agarose/EtBr gel electrophoresis.

Electrophysiology. Experiments were performed at room temperature, $22-25^{\circ} \mathrm{C}$, within $24 \mathrm{hr}$ of cell isolation. Cells with seal resistance of $<3$ $\mathrm{G} \Omega$ and access resistance of $>50 \mathrm{M} \Omega$ were discarded. Membrane currents were amplified (Axopatch 200A, Axon Instruments, Foster City, $\mathrm{CA}$ ) and sampled on-line at $5 \mathrm{kHz}$ using a microcomputer equipped with a digitizing board (Digidata 1200A, Axon Instruments) and running Clampex software (version 8.0, Axon Instruments). Membrane currents were recorded in intact cells using both the cell-attached and the nystatin-perforated whole-cell configurations (Korn et al., 1991), and in cell-free isolated membrane patches, using both the inside-out and outside-out configurations. Currents were measured during step pulses ( $600 \mathrm{msec}$ ) or during ramp pulses $(-140$ to $+50 \mathrm{mV}$ at $0.32 \mathrm{mV} / \mathrm{msec}$ ) from a holding potential of $-67 \mathrm{mV}$. Patch-clamp pipettes, pulled from borosilicate glass (Kimax, Fisher Scientific, Pittsburgh, PA), had resistances of 6-8 $\mathrm{M} \Omega$ for single-channel recordings and 2-4 $\mathrm{M} \Omega$ for experiments using the nystatin-perforated whole-cell technique. The bath electrode was an $\mathrm{Ag} / \mathrm{AgCl}$ pellet (Clark Electromedical, Reading, UK) that was placed directly in the bath. We used a recording chamber in which bath solution flowed constantly and could be exchanged within $15-25 \mathrm{sec}$.

Recording solutions. For whole-cell macroscopic recordings, we used a nystatin perforated-patch technique with a bath solution containing (mM): $130 \mathrm{NaCl}, 10 \mathrm{KCl}, 1 \mathrm{CaCl}_{2}, 1 \mathrm{MgCl}_{2}, 32.5$ HEPES, 12.5 glucose, $\mathrm{pH}$ 7.4. The pipette solution contained (in $\mathrm{mm}$ ): $55 \mathrm{KCl}, 75 \mathrm{~K}_{2} \mathrm{SO}_{4}, 8 \mathrm{MgCl}_{2}$, and 10 HEPES, pH 7.2. Nystatin $(50 \mathrm{mg}$ ) (Calbiochem) was dissolved in $1 \mathrm{ml}$ of dimethylsulfoxide (DMSO). Working solutions were made before the experiment by adding $16.5 \mu$ l of nystatin stock solution to $5 \mathrm{ml}$ of the base pipette solution to yield a final concentration of nystatin of 165 $\mu \mathrm{g} / \mathrm{ml}$ and DMSO $3.3 \mu \mathrm{l} / \mathrm{ml}$.

For cell-attached patch recording, we used a bath solution containing (in mM): $130 \mathrm{NaCl}, 10 \mathrm{KCl}, 1 \mathrm{CaCl}_{2}, 1 \mathrm{MgCl}_{2}, 32.5$ HEPES, 12.5 glucose, $\mathrm{pH}$ 7.4. The pipette solution contained (in $\mathrm{mm}$ ): $145 \mathrm{CsCl}, 1 \mathrm{MgCl}_{2}, 0.2$ $\mathrm{CaCl}_{2}, 5$ EGTA, 10 HEPES, pH 7.3. The measured osmolarity of the extracellular solution was $\sim 300 \mathrm{mOsm}$ (Precision Systems, Natick, MA).

For inside-out patch recording, we used a bath solution containing (in $\mathrm{mm}$ ): $145 \mathrm{CsCl}, 1.5 \mathrm{CaCl}_{2}, 1 \mathrm{MgCl}_{2}, 5 \mathrm{EGTA}, 32.5 \mathrm{HEPES}, 12.5$ glucose, $\mathrm{pH}$ 7.4. The pipette solution contained (in $\mathrm{mm}$ ): $145 \mathrm{CsCl}, 1 \mathrm{MgCl}_{2}, 0.2$ $\mathrm{CaCl}_{2}, 5$ EGTA, 10 HEPES, pH 7.3.

For outside-out patch recording, we used the pipette solution, which contained (in mM): $145 \mathrm{CsCl}, 1 \mathrm{MgCl}_{2}, 0.2 \mathrm{CaCl}_{2}, 1$ ATP 1, 5 EGTA, 10 HEPES, pH 7.3. The standard bath solution contained (in mM): $145 \mathrm{CsCl}$, $1.5 \mathrm{CaCl}_{2}, 1 \mathrm{MgCl}_{2}, 5$ EGTA, 32.5 HEPES, 12.5 glucose, $\mathrm{pH}$ 7.4.

SUR activators ( $\mathrm{K}_{\mathrm{ATP}}$ channel openers) diazoxide, pinacidil, and cromakalin, and sulfonylureas, tolbutamide and glibenclamide, were obtained from Sigma and dissolved in DMSO at concentrations of 10-100 mM for stock solutions. Working solutions were made before the experiment by adding stock solution to the bath solution to yield the desired 

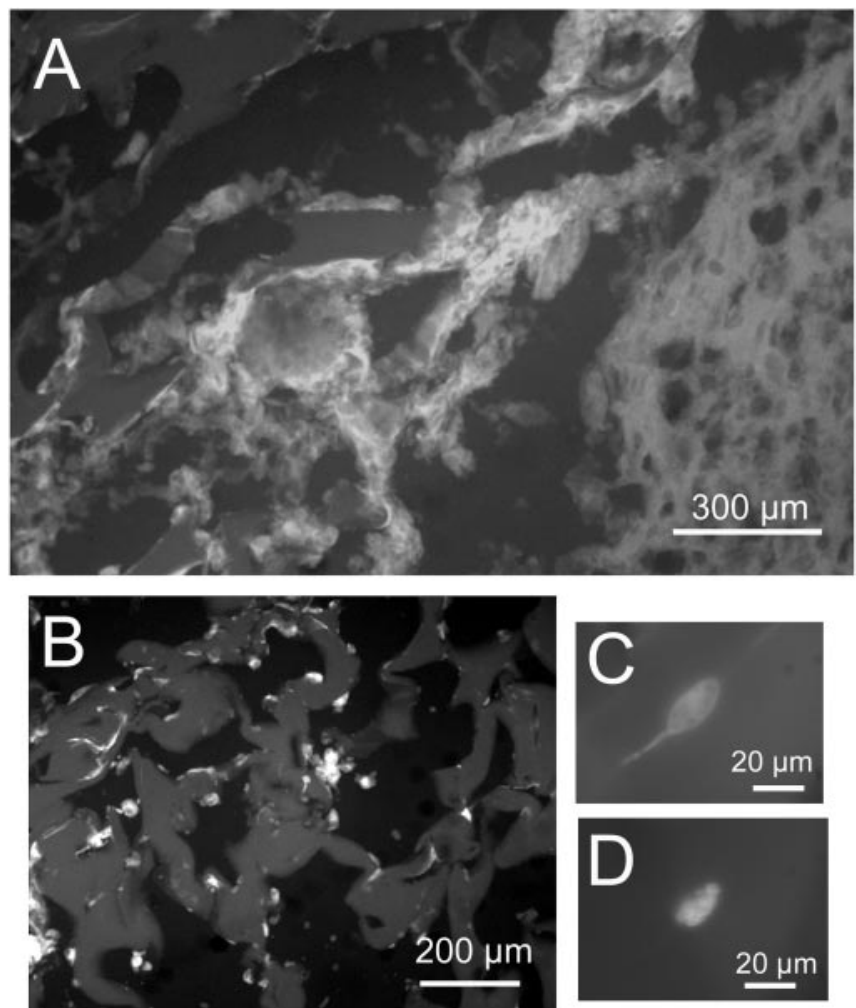

Figure 1. Binding of glibenclamide. A, Fluorescence image of gliotic capsule $8 \mathrm{~d}$ after injury labeled with FITC-tagged glibenclamide; parenchyma is shown in bottom right corner, gelatin sponge is shown in top left, and gliotic capsule is arranged diagonally. $B$, Fluorescence image of gelatin sponge at higher power shows labeled cells lining cavities of the sponge. C, D, Highpower fluorescence image of a single cell showing FITC-tagged glibenclamide $(C)$ and antiGFAP (D) immunolabeling of the same cell.

concentration. (DMSO was tested in separate experiments and was found to be without effect at the concentrations used.) Antibodies used for electrophysiological experiments, which were the same as those used for immunolabeling, included anti-SUR1-antibody (catalog \#sc-5789) and anti-Kir6.1 antibody (catalog \#sc-11224), both from Santa Cruz Biotechnology.

Data analysis. Single-channel amplitudes used to calculate slope conductances were obtained by fitting a Gaussian function to an all-points amplitude histogram of records obtained at various potentials. To calculate open-channel probability $\left(n \times p_{\mathrm{o}}\right)$ at various potentials and with different test agents, the all-points histogram was fit to a Gaussian function, and the area under the fitted curve for the open channel was divided by the area under the fitted curve for the closed plus open channel.

For dwell time histograms, we used records with single-channel openings obtained during test pulse to $E_{\mathrm{m}}=-80 \mathrm{mV}$, filtered at $1 \mathrm{kHz}(-3$ $\mathrm{dB}$; rise time, $330 \mu \mathrm{sec}$ ). As suggested previously (Sigworth and Sine, 1987), the distributions of open or closed times were compiled after conversion to the logarithm of the time interval, using 10 bins per decade for the abscissa of the histogram and a square root axis for the ordinate. Using this transformation, the probability density function (pdf) for a double exponential distribution is $\mathrm{pdf}=\left\{a_{1} \times \exp \left[z_{1}-\exp \left(z_{1}\right)\right]+a_{2} \times\right.$ $\left.\exp \left[z_{2}-\exp \left(z_{2}\right)\right]\right\}^{0.5}$, where $z_{1}=\left[\ln (t)-\ln \left(\tau_{1}\right)\right], z_{2}=\left[\ln (t)-\ln \left(\tau_{2}\right)\right]$, $t$ is time, and $a_{1}$ and $a_{2}$ relate to the number of open events having time constants of $\tau_{1}$ and $\tau_{2}$, respectively.

Junction potentials, which generally did not exceed $5 \mathrm{mV}$, were subtracted when appropriate. Holding currents were not subtracted from any of the recordings. Concentration-response data were fit to a standard logistic equation using the Levenberg-Marquardt algorithm as implemented in Origin 7.0 (Microcal Software, Northampton, MA). Data are given as mean $\pm \mathrm{SD}$.
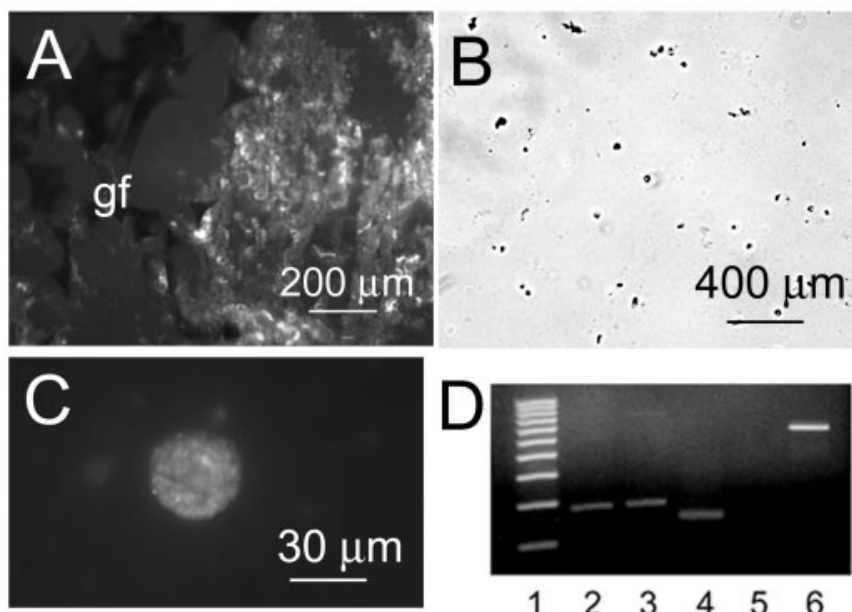

Figure 2. Immunolabeling and RT-PCR for SUR1 in gliotic capsule and freshly isolated reactive astrocytes. $A$, Immunofluorescence image of gliotic capsule labeled using anti-SUR1 antibody; Gelfoam sponge ( $\mathrm{gf}$ ) is shown at left. $B, C$, Low-power ( $B$ ) and high-power ( $C$ views of freshly isolated astrocytes immunolabeled using anti-SUR1 antibody and visualized using chromagenic $(B)$ or fluorescent $(C$ secondary antibodies. D, RT-PCR for SUR1 and SUR2 in freshly isolated astrocytes and control tissues; SUR1-mRNA was present in insulinoma RIN-m5f cells (lane 2) and astrocytes (lane 3); SUR2 was present in cardiomyocytes (lane 4) but not in astrocytes (lane 5); lane 1 is the 100 bp DNA size marker, and lane 6 is the $\beta$-actin (540 bp) RT-PCR positive control reaction.

\section{Results}

\section{Glibenclamide binding}

We used FITC-tagged glibenclamide to evaluate sulfonylurea binding sites, DAPI to label cell nuclei, and anti-GFAP antibodies as a marker of reactive astrocytes at the site of brain injury. Glibenclamide binding was found to be prominent in the layer of tissue corresponding to the gliotic capsule surrounding the gelatin sponge (Fig. 1A). Scattered areas of positive label were also found within the sponge itself (Fig. $1 B$ ). At higher magnification, glibenclamide-labeled cells were observed (Fig. $1 C$ ) that were invariably positive for GFAP (Fig. $1 D$ ), identifying them as reactive astrocytes. Overall, we estimated that $>80 \%$ of the cells encapsulating the sponge and present within the sponge, as identified by DAPI, showed binding of glibenclamide. Specificity of binding was assessed by pretreating tissue sections with unlabeled glibenclamide before exposing them to FITC-tagged glibenclamide, a protocol that yielded sections with no fluorescent label (data not shown). In brain adjacent to the injury, no glibenclamide binding was apparent (Fig. 1A), although abundant label for GFAP was present (Perillan et al., 1999). These data indicated that sulfonylurea binding sites, which are not normally present in subcortical white matter, were expressed abundantly in GFAP-positive cells encapsulating and invading the foreign body after traumatic injury.

\section{Immunolabeling and RT-PCR for SUR1 and SUR2}

To further characterize the sulfonylurea binding sites, we assessed for expression of sulfonylurea receptors. Eight days after injury, strong labeling with anti-SUR1 antibody was found in the gliotic capsule surrounding the gelatin sponge (Fig. 2A). The gliotic capsule was harvested and, as reported previously, subjected to enzymatic digestion to release NRAs (Chen and Simard, 2001). Most of the cells released by this procedure are the NR1As, which are large, round, phase bright, and GFAP-positive and express the $\mathrm{NC}_{\text {Ca-ATP }}$ channel (Chen and Simard, 2001). Examination at low magnification of fields of cells labeled with anti-SUR1 antibody 


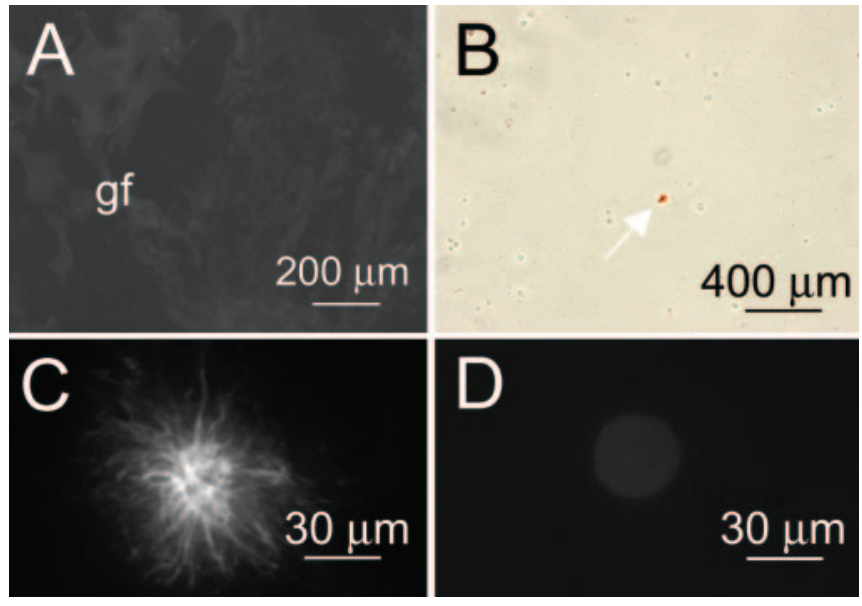

Figure 3. Immunolabeling for Kir6.1 in gliotic capsule and freshly isolated reactive astrocytes. $A$, Immunofluorescence image of gliotic capsule labeled using anti-Kir6.1 antibody; Gelfoam sponge ( $\mathrm{g} f$ ) is shown at left; same tissue section as in Figure 2A. B, Low-power view of freshly isolated astrocytes immunolabeled using anti-Kir6.1 antibody and visualized using chromagenic secondary antibody; arrow points to the only positive cell in the field. C, D, Highpower views of individual cells immunolabeled using anti-Kir6.1 antibody and visualized using fluorescent secondary antibody; only rare stellate cells $(C)$ were labeled, whereas the more common large round cells $(D)$ were not.

confirmed that nearly all cells expressed SUR1 (Fig. 2B). SUR1positive cells examined at high magnification were invariably the large round cells typical of NR1A (Fig. 2C). Tissues and isolated NRAs were uniformly negative when labeled with anti-SUR2 antibody (data not shown).

Preparations of NRA, enriched using gradient centrifugation to remove erythrocytes, were used in RT-PCR experiments to assess transcription of SURx mRNA. Insulinoma RIN-m5f cells and rat cardiomyocytes, which constitutively express $\mathrm{K}_{\mathrm{ATP}}$ channels (Aguilar-Bryan et al., 1995), were used as positive controls for SUR1 and SUR2, respectively. Total RNA from NRA, RIN$\mathrm{m} 5 \mathrm{f}$ cells, and cardiomyocytes was reverse transcribed with oligo-dT primers to obtain cDNA, which was then amplified by PCR using primers unique for SUR1 and SUR2, with the SUR2 sequence common to SUR2A, SUR2B, and SUR2C (Inagaki et al., 1996). Electrophoresis showed amplicons of the predicted size for SUR1 from both RIN-m5f cells and NRA (Fig. $2 D$, lanes 2 and 3 , respectively). Amplicons for SUR2 were found with control cardiomyocytes but not with NRA (Fig. $2 D$, lanes 4 and 5, respectively). Sequencing of the amplicon from NRA obtained from the agarose gel showed a 100\% match with the corresponding $181 \mathrm{bp}$ SUR1 sequence in the GenBank database. These data were consistent with SUR1, but not SUR2A, SUR2B, or SUR2C, mRNA transcription in NRA.

\section{Immunolabeling for Kir6.1 and Kir6.2}

The SURx are known to complex principally with Kir6.1 or Kir6.2 to form functional $\mathrm{K}_{\mathrm{ATP}}$ channels (Aguilar-Bryan et al., 1995; Isomoto et al., 1996). We thus performed immunolabeling experiments on NRA using anti-Kir6.1 and anti-Kir6.2 antibodies to assess for the presence of $\mathrm{K}_{\mathrm{ATP}}$ channels. Tissue sections were typically negative for both Kir6.1 (Fig. 3A) and Kir6.2 (data not shown). Similarly, for the majority of isolated cells, no labeling for either Kir6.1 (Fig. 3B) or Kir6.2 (data not shown) was evident, although rarely an occasional cell was labeled with anti-Kir6.1 antibody (Fig. 3B, arrow). Examination of positive cells at high magnification showed that they were invariably stellate-shaped astrocytes (Fig. 3C), which have previously been shown to express

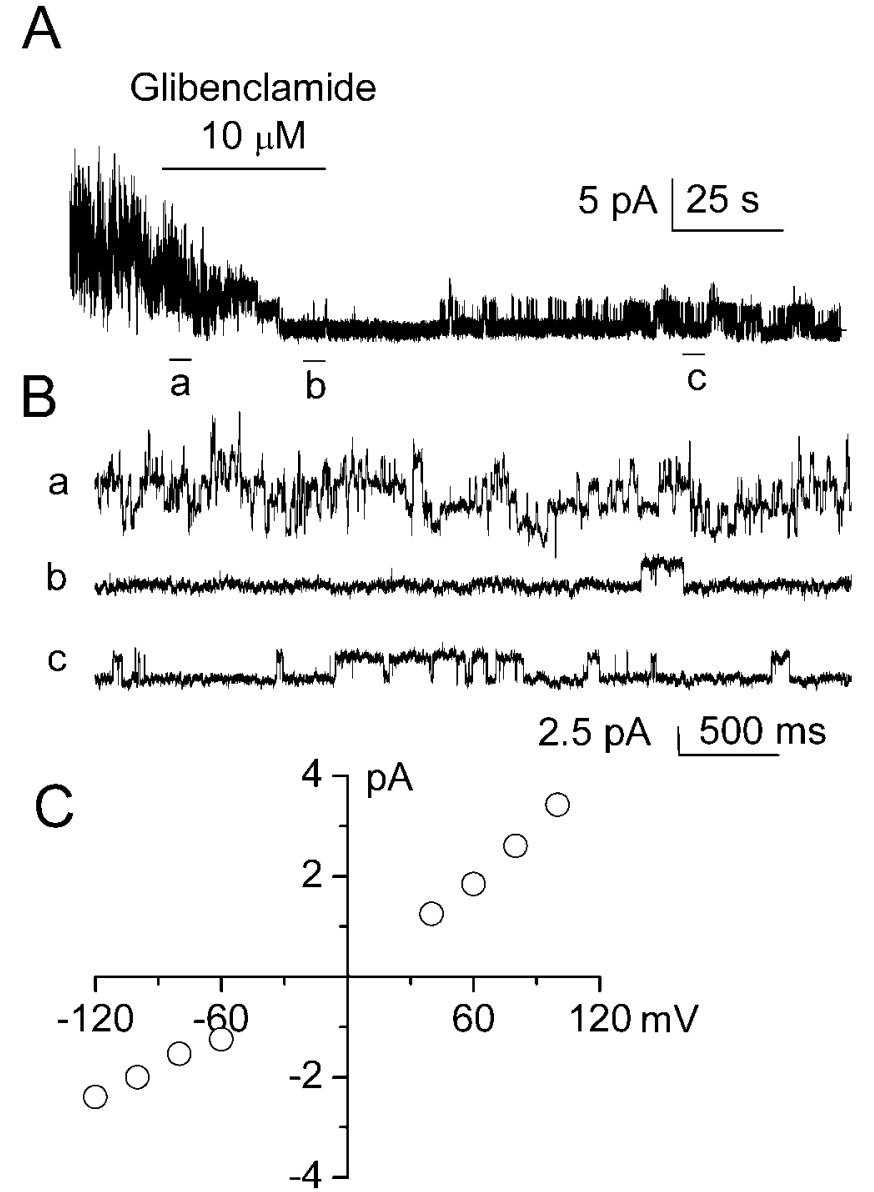

Figure 4. Glibenclamide blocks $35 \mathrm{pS} \mathrm{NC} \mathrm{C}_{\text {a-ATP }}$ channel in native reactive astrocytes. $A$, Single-channel record obtained at $-100 \mathrm{mV}$ in an inside-out patch at low temporal resolution, before, during, and after application of $10 \mu \mathrm{m}$ glibenclamide, as indicated by the horizontal bar; $\mathrm{Cs}^{+}$in both bath and pipette, with $1 \mu \mathrm{MCa}{ }^{2+}$ in the bath. $B$, Records from $A$ at higher temporal resolution, before $(a)$, during $(b)$, and after $(c)$ addition of glibenclamide; channel openings are plotted upward. C, Plot of single-channel conductance as a function of membrane potential, indicating slope conductance of $35 \mathrm{pS}$ for glibenclamide-sensitive channel.

Kir6.1 $\mathrm{K}_{\text {AтP }}$ channels (Thomzig et al., 2001). By contrast, the more common large round cells, i.e., the NR1As, were not labeled with anti-Kir6.1 antibody (Fig. 3D). Notably, stellate astrocytes, which are obtained only in very small numbers in our model of injury, exhibit a different electrophysiological profile than NR1As and do not exhibit currents attributable to the $\mathrm{NC}_{\mathrm{Ca}-\mathrm{ATP}}$ channel (Perillan et al., 2000). Lack of Kir6.1 and Kir6.2 labeling in NR1As indicated that $\mathrm{K}_{\mathrm{ATP}}$ channels were not present in these cells, suggesting a different role for SUR1.

Sulfonylureas block the $\mathrm{NC}_{\mathrm{Ca}-\mathrm{ATP}}$ channel

To this point, we had found that the $\mathrm{NC}_{\mathrm{Ca}-\mathrm{ATP}}$ channel in NR1As and the $\mathrm{K}_{\mathrm{ATP}}$ channel in pancreatic $\beta$ cells bore important similarities: both channels exhibited similar sensitivity to the adenine nucleotides ATP, ADP, and AMP (Chen and Simard, 2001), and both channels were found in cells that expressed SUR1. Conversely, they bore an important difference: only the pancreatic $\beta$ cells and not the NR1As expressed Kir6.x. We thus hypothesized that the $\mathrm{NC}_{\text {Ca-ATP }}$ channel in NR1As might be formed from a non-Kir6.x pore-forming moiety that was regulated by SUR1. To test this, we performed a series of pharmacological and electrophysiological experiments designed to mimic experiments that 
A

[Tolbutamide]
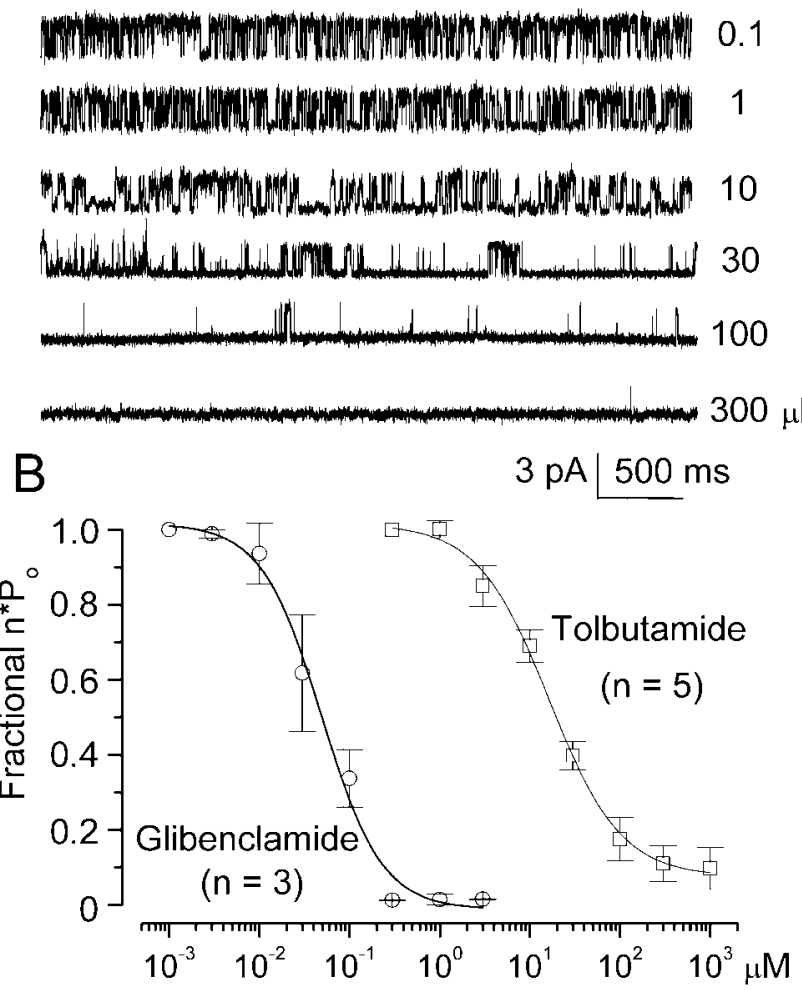

Figure 5. Sulfonylureas block $\mathrm{NC}_{\mathrm{Ca} \text {-ATP }}$ channel in native reactive astrocytes in a dosedependent manner consistent with sulfonylurea receptor type 1. A, Single-channel records obtained at $-120 \mathrm{mV}$ in an inside-out patch with different concentrations of tolbutamide, as indicated on the right; $\mathrm{Cs}^{+}$in both bath and pipette, with $1 \mu \mathrm{M} \mathrm{Ca}{ }^{2+}$ in the bath; channel openings are plotted upward. $B$, Concentration-response data (mean $\pm \mathrm{SE}$ ) for fractional inhibition of channel open probability $\left(n \times p_{0}\right)$ by glibenclamide and tolbutamide; fit to logistic equation indicated half-maximum effect at $48 \mathrm{~nm}$ and $16.1 \mu \mathrm{m}$ for glibenclamide and tolbutamide, respectively, with similar Hill coefficients of $\sim 1.3$.

have been used previously to characterize $\mathrm{K}_{\mathrm{ATP}}$ channels regulated by SUR1. For these experiments, care was taken to study only NR1As, which are readily identified by their large, round, phase-bright appearance, and to exclude stellate astrocytes as well as small phase-dark type R2 astrocytes (Dalton et al., 2003).

One hallmark of SUR1-regulated $\mathrm{K}_{\mathrm{ATP}}$ channels, when assessed either in pancreatic $\beta$ cells or in expression systems expressing SUR1 plus Kir6.2, is channel block by the sulfonylureas, glibenclamide and tolbutamide (Aguilar-Bryan et al., 1995; Inagaki et al., 1996). We used inside-out patches to assess block of the $\mathrm{NC}_{\text {Ca-ATP }}$ channels by sulfonylureas. More than $90 \%$ of patches excised into solution with $1 \mu \mathrm{M} \mathrm{Ca}^{2+}$ and without ATP exhibit 35 pS activity characteristic of this channel (Chen and Simard, 2001). We studied patches using $\mathrm{Cs}^{+}$as the charge carrier to assure that no $\mathrm{K}^{+}$channel, specifically $\mathrm{K}_{\mathrm{ATP}}$, was contributing to patch activity. With no ATP and $1 \mu \mathrm{M} \mathrm{Ca}^{2+}$ in the bath, patches exhibited vigorous openings caused by multiple channels (Fig. $4 A, B a$ ). Measurements of single-channel conductance at different potentials and calculation of slope conductance confirmed the presence of a $35 \mathrm{pS}$ cation channel, consistent with the properties reported previously for this channel (Fig. 4C). Channel availability in this patch was profoundly diminished by subsequent addition of $10 \mu \mathrm{M}$ glibenclamide (Fig. $4 A, B b$ ), an effect that was partially reversed on washout of drug (Fig. $4 B c$ ). Another sulfonylurea, tolbutamide, was also found to inhibit $\mathrm{NC}_{\text {Ca-ATP }}$ channel activity. At low concentrations $(\leq 1 \mu \mathrm{M})$, tol-

\section{OPEN PROBABILITY}
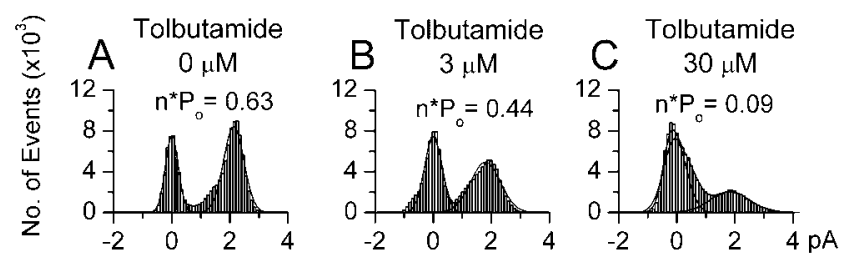

\section{OPEN TIMES}
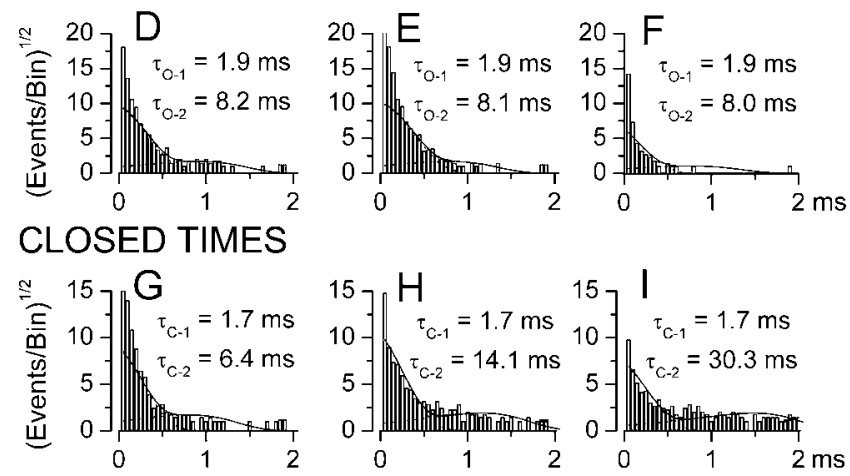

Figure 6. Tolbutamide inhibits $\mathrm{NC}_{\text {Ca-ATP }}$ channel by affecting kinetics of channel closing. $A-C$, The probability of channel opening $\left(n \times p_{0}\right)$ in the presence of $0(A), 3 \mu \mathrm{M}(B)$, and $30 \mu \mathrm{M}$ (C) tolbutamide. $D-F$, The distribution of open-channel dwell times in the presence of $O(D), 3$ $\mu \mathrm{M}(E)$, and $30 \mu \mathrm{M}(F)$ tolbutamide; values of $\tau_{0-1}$ and $\tau_{0-2}$ are shown for each concentration. $G-I$, The distribution of closed-channel dwell times in the presence of $0(G), 3 \mu \mathrm{M}(H)$, and 30 $\mu \mathrm{M}(/)$ tolbutamide; values of $\tau_{\mathrm{c}-1}$ and $\tau_{\mathrm{c}-2}$ are shown for each concentration. All data are from the same patch, with histograms compiled from continuous 1-min-long recordings at $-80 \mathrm{mV}$ at each concentration of drug; each probability density histogram was plotted with a square root axis for the ordinate and a logarithmic axis for the abscissa; solid lines represent the corresponding probability density functions (equation in Materials and Methods) with time constants indicated in each panel; all time constants derived from fits to pooled data from three to five patches, with pdf values scaled appropriately for the data from the single patch shown.

butamide had no obvious effect on the channel, but as the concentration was increased from 1 to $300 \mu \mathrm{M}$, channel openings were increasingly diminished (Fig. 5A).

We measured the open-channel probability $\left(n \times p_{\mathrm{o}}\right)$ at different concentrations of both glibenclamide and tolbutamide, normalized these values to those obtained at $1 \mathrm{~nm}$ and $0.1 \mu \mathrm{M}$, for glibenclamide and tolbutamide, respectively, and fitted these values to a standard logistic equation. As shown in Figure $5 B$, the $\mathrm{NC}_{\text {Ca-ATP }}$ channel was blocked by sulfonylureas in a dosedependent manner. With tolbutamide, half-maximum inhibition $\left(\mathrm{EC}_{50}\right.$ ) was observed at $16.1 \mu \mathrm{M}$ with a Hill coefficient of 1.3 , and channel activity was completely lost at concentrations $>300$ $\mu \mathrm{M}$. With glibenclamide, the $\mathrm{EC}_{50}$ was $48 \mathrm{~nm}$ with a Hill coefficient of 1.2 (Fig. 5B). Notably, the sensitivity to block observed here with the $\mathrm{NC}_{\text {Ca-ATP }}$ channel in NR1As with both sulfonylureas corresponded closely to that reported in pancreatic $\beta$ cells and in expression systems with SUR1, but not with SUR2 (Fujita and Kurachi, 2000).

\section{Mechanism of channel inhibition by sulfonylureas}

Characterizing the mechanism of sulfonylurea inhibition can be informative regarding the identity of the SUR isoform. With Kir6.2 as the channel moiety, inhibition does not occur directly by block of the channel pore but by an allosteric mechanism that affects channel kinetics. On the basis of analysis of channel kinetics, sulfonylurea-mediated inhibition of Kir6.2 via SUR1 is distinguishable from inhibition via SUR2 (Babenko et al., 1999).

We performed single-channel analysis to characterize the 


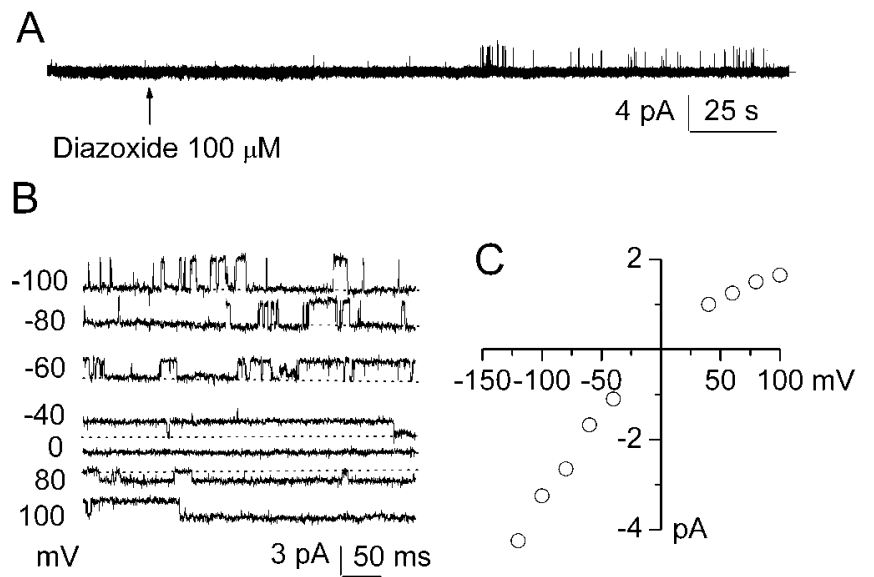

Figure 7. Diazoxide activates $\mathrm{NC}_{\mathrm{Ca} \text {-ATP }}$ channel in native reactive astrocytes. $A$, Singlechannel records obtained at $-80 \mathrm{mV}$ in a cell-attached patch at low temporal resolution before and after addition of $100 \mu \mathrm{m}$ diazoxide; channel openings are plotted upward. B, Singlechannel records from a different cell-attached patch showing channel openings at different membrane potentials after application of $100 \mu \mathrm{m}$ diazoxide; closed state is denoted by dotted lines. C, Plot of single-channel amplitude (mean of 7 patches) versus membrane potential with fit to linear equation indicated a slope conductance of $\sim 35 \mathrm{pS}$ at negative potentials, with weak inward rectification.

mechanism of block of sulfonylureas on the $\mathrm{NC}_{\mathrm{Ca}-\mathrm{ATP}}$ channel. First, it was evident from inspection of single-channel records that channel amplitude was not reduced with increasing concentration of drug (Fig. 5A). A reduction in channel amplitude is frequently observed when a blocking agent enters the pore of the channel and, with rapid off-time kinetics, produces a "flickery" block. This is the presumed mechanism for block of the $\mathrm{NC}_{\mathrm{Ca}-\mathrm{ATP}}$ channel by intracellular $\mathrm{Mg}^{2+}$ (Chen and Simard, 2001), but it appeared not to be relevant to sulfonylurea-mediated inhibition of the $\mathrm{NC}_{\mathrm{Ca}-\mathrm{ATP}}$ channel.

Open-channel dwell times were analyzed. As characterized previously, the $\mathrm{NC}_{\mathrm{Ca}-\mathrm{ATP}}$ channel exhibits two open states, with dwell times $\left(\tau_{\mathrm{o} 1}\right.$ and $\left.\tau_{\mathrm{o} 2}\right)$ of 2 and $8 \mathrm{msec}$, with $28 \%$ of openings being from the closed to the long open state (Chen and Simard, 2001). Similar observations were made here before drug application, with the example shown exhibiting an open probability $\left(n \times p_{\mathrm{o}}\right)$ of 0.63 , with values of $\tau_{\mathrm{o} 1}$ and $\tau_{\mathrm{o} 2}$ of 1.9 and $8.2 \mathrm{msec}$, and with $31 \%$ of openings being from the closed to the long open state (Fig. 6A,D). After successive application of $3 \mu \mathrm{M}$ (Fig. $6 B, E)$ and $30 \mu \mathrm{M}$ (Fig. $6 C, F$ ) tolbutamide, $n \times p_{\mathrm{o}}$ decreased to 0.44 and 0.09 , respectively, and the number of openings from the closed to the long open state diminished to 23 and 10\%, respectively (Fig. $6 E, F)$; however, values of $\tau_{\mathrm{o} 1}$ and $\tau_{\mathrm{o} 2}$ were not appreciably affected by drug $\left(\tau_{\mathrm{o} 1}=1.9\right.$ and $1.9 \mathrm{msec}$ and $\tau_{\mathrm{o} 2}=8.1$ and $8.0 \mathrm{msec}$ at 3 and $30 \mu \mathrm{M}$ tolbutamide, respectively), indicating minimal effect on open-channel dwell times.

Closed-channel dwell times were also analyzed. Data from the same patch showed that both the duration and frequency of long closures increased with drug. Before drug application, the $\mathrm{NC}_{\text {Ca-ATP }}$ channel exhibited two closed states, with dwell times $\left(\tau_{\mathrm{c} 1}\right.$ and $\left.\tau_{\mathrm{c} 2}\right)$ of 1.7 and $6.3 \mathrm{msec}$, with the long closed state representing $18 \%$ of closures (Fig. $6 G$ ). With $3 \mu \mathrm{M}$ (Fig. $6 H$ ) and 30 $\mu \mathrm{M}$ (Fig. 6I) tolbutamide, the time constant for the long closed state $\left(\tau_{\mathrm{c} 2}\right)$ increased to 14.1 and $30.3 \mathrm{msec}$, respectively, and the fraction of closings represented by the long closed state increased to 33 and $42 \%$, respectively. Similar results were observed in four other patches. This form of channel inhibition, i.e., no effect on open-channel dwell times and a progressive increase in long clo-
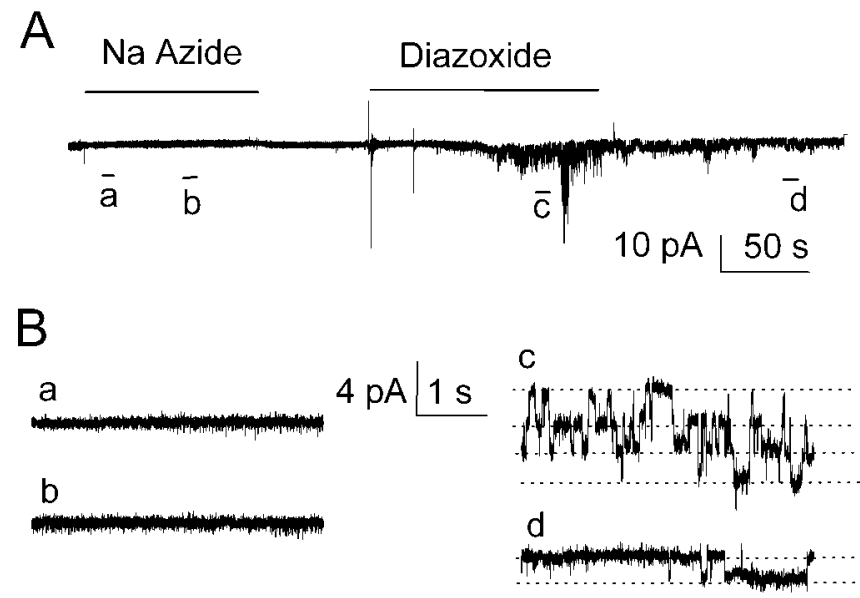

Figure 8. Diazoxide, but not Na azide, activates the $\mathrm{NC}_{\mathrm{Ca} \text {-ATP }}$ in cell-free membrane patches. $A, B$, Single-channel records obtained at $-80 \mathrm{mV}$ in an outside-out patch at low temporal resolution $(A)$ and at higher temporal resolution $(B)$, showing that Na azide (1 $\mathrm{mm}$ ) did not activate the channel in this configuration but that diazoxide (100 $\mu \mathrm{m})$ did; records in $B$ were taken from the portions indicated in $A$ by the corresponding letters; channel openings are plotted downward.

sures, is typical of the inhibition produced by sulfonylureas acting on the $\mathrm{K}_{\mathrm{ATP}}$ channel in pancreatic $\beta$ cells (Gillis et al., 1989; Babenko et al., 1999).

\section{SUR-mediated activation of $\mathrm{NC}_{\text {Ca-ATP }}$ channel}

Another hallmark of SUR1-regulated $\mathrm{K}_{\mathrm{ATP}}$ function, when assessed either in pancreatic $\beta$ cells or in expression systems expressing SUR1 plus Kir6.2, is channel activation by the SUR activator diazoxide, with weak or no activation by pinacidil or cromakalin, which preferentially activate SUR2 (Fujita and Kurachi, 2000). We found previously that cell-attached patches from healthy NR1As are usually quiet and that ATP depletion after exposure to $\mathrm{Na}$ azide or $\mathrm{NaCN}$ plus 2-deoxyglucose was required to activate $\mathrm{NC}_{\mathrm{Ca}-\mathrm{ATP}}$ channels in this recording configuration (Chen and Simard, 2001). We used cell-attached patches to examine the effect of diazoxide on the $\mathrm{NC}_{\mathrm{Ca}-\mathrm{ATP}}$ channel, with $\mathrm{Cs}^{+}$again being used in the pipette to prevent any contribution of $\mathrm{K}^{+}$channels to the current. As found previously, typical cellattached patches were mostly silent, but addition of $100 \mu \mathrm{M}$ diazoxide to the bath elicited single-channel events soon after addition of drug (Fig. 7A). Single-channel events recorded at different membrane potentials after diazoxide are shown in Figure $7 B$, with the magnitude of the open-channel current plotted as a function of membrane potential in Figure 7C. Diazoxide activated a single-channel conductance of $\sim 35 \mathrm{pS}$ that exhibited weak inward rectification when measured in the cell-attached configuration, similar to previous observations on channel activation accompanying depletion of $[\mathrm{ATP}]_{\mathrm{i}}$ (Chen and Simard, 2001). Similar findings were made in 8 of 18 cell-attached patches exposed to diazoxide, whereas both pinacidil $(10 \mu \mathrm{M} ; n=7)$ and cromakalin (100 $\mu \mathrm{M} ; n=4)$ were without effect in similar cellattached patch experiments, consistent with SUR1- but not SUR2-mediated channel activation.

We reported previously that $\mathrm{Na}$ azide activated the $35 \mathrm{pS}$ $\mathrm{NC}_{\text {Ca-ATP }}$ channel in the cell-attached configuration but not in outside-out patches with $1 \mathrm{mM}$ ATP in the pipette, consistent with a mechanism involving ATP depletion rather than direct activation by $\mathrm{Na}$ azide (Chen and Simard, 2001). Having shown activation by diazoxide in a cell-attached configuration, we next 
A
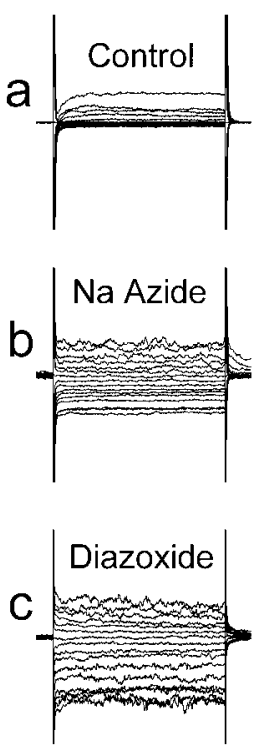

B
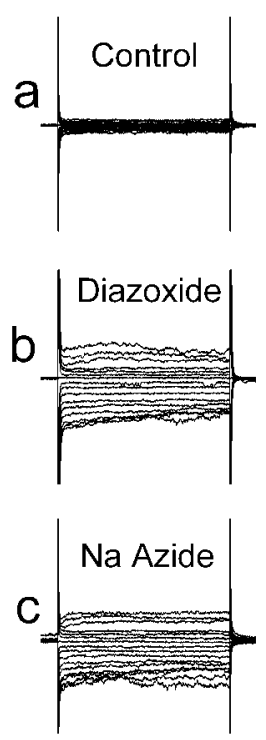

C
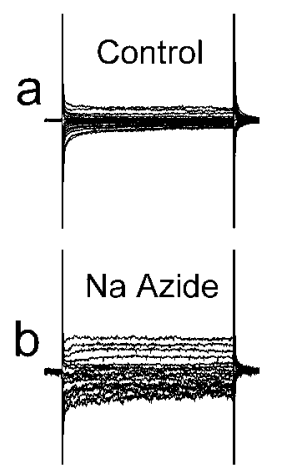

Na Azide

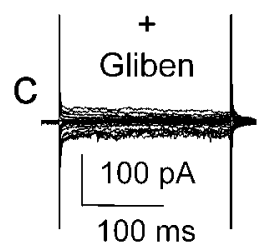

Figure 9. Both $\mathrm{Na}$ azide and diazoxide activate the same $\mathrm{NC}_{\mathrm{Ca} \text {-ATP }}$ current in the whole-cell configuration. $A$, Currents during step pulses ( -120 to $+40 \mathrm{mV}$ in $10 \mathrm{mV}$ steps) under control conditions ( $a$ ), after addition of $1 \mathrm{~mm}$ Na azide $(b)$, and after addition of $100 \mu \mathrm{m}$ diazoxide ( $c$ ). $B$, Currents during step pulses under control conditions (a), after addition of $100 \mu \mathrm{m}$ diazoxide (b), and after addition of $1 \mathrm{~mm} \mathrm{Na}$ azide (c). C, Currents during step pulses under control conditions ( $a$ ), after addition of $1 \mathrm{~mm} \mathrm{Na}$ azide ( $b$ ), and after addition of $1 \mu \mathrm{m}$ glibenclamide ( $c$ ).

sought to determine whether diazoxide would activate the channel in outside-out patches in the presence of ATP. When studied with $1 \mathrm{~mm}$ ATP and $1 \mu \mathrm{M} \mathrm{Ca}{ }^{2+}$ in the pipette, and $\mathrm{Cs}^{+}$on both inside and outside membrane surfaces, application of $1 \mathrm{mM} \mathrm{Na}$ azide to outside-out patches did not cause activation of any channel over the course of 2-3 min, as expected (Fig. 8A,B). After washout of $\mathrm{Na}$ azide, however, subsequent application of $100 \mu \mathrm{M}$ diazoxide to the same patch resulted in brisk activation of channel activity (Fig. $8 A c, B c$ ), with partial loss of activity after washout of drug (Fig. $8 A d, B d$ ). Similar results were obtained in seven additional experiments. Thus, activation by diazoxide did not require a metabolically intact whole cell, consistent with diazoxide acting directly on the channel (Harvey et al., 1999), and in contradistinction to the action of $\mathrm{Na}$ azide, the effect of which is mediated via ATP depletion.

We also sought to show that the channel turned on in whole cells by ATP depletion was the same channel as that turned on by diazoxide. For these experiments, a nystatin perforated-patch method was used to assure that metabolic disruption would come from drug application and not from cell dialysis. As reported previously (Chen and Simard, 2001), recordings obtained during step pulses showed significantly larger currents several minutes after $\mathrm{Na}$ azide ( $1 \mathrm{~mm}$ ) compared with control (Fig. 9Aa,Ab). Subsequent application of $100 \mu \mathrm{M}$ diazoxide had relatively little effect, augmenting the inward current slightly or not at all in different experiments (Fig. 9Ac), suggesting that diazoxide was acting on the same channel as had already been turned on by $\mathrm{Na}$ azide-induced $[\mathrm{ATP}]_{\mathrm{i}}$ depletion. Reversing the order of drug application gave a similar result. Diazoxide turned on a macroscopic current (Fig. 9Ba, Bb), and subsequent application of $\mathrm{Na}$ azide had relatively little effect (Fig. 9Bc), thus suggesting that $\mathrm{Na}$ azide-induced $[\mathrm{ATP}]_{\mathrm{i}}$ depletion was acting on the same channel as had already been turned on by diazoxide.

\section{Control}

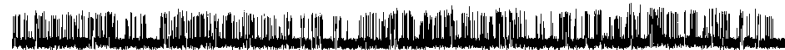
$1 \mu \mathrm{M}$ Glibenclamide

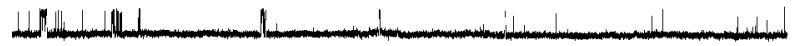

$<\mathrm{C}$

$100 \mu \mathrm{g} / \mathrm{ml}$ Trypsin

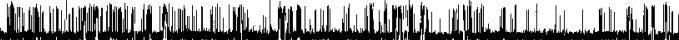

$<\mathrm{C}$

$1 \mu \mathrm{M}$ Glibenclamide

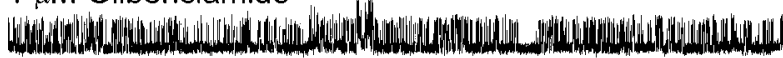

$1 \mathrm{mM}$ ATP

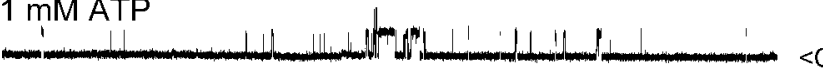

ATP washout

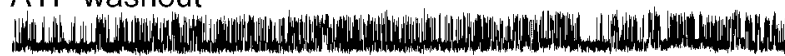

$<\mathrm{C}$

\section{$5 \mathrm{pA} \quad 3 \mathrm{~s}$}

Figure 10. Tryptic digestion removes glibenclamide but not ATP inhibition of $\mathrm{NC}_{\mathrm{Ca}-\mathrm{ATP}}$ channel. Currents were recorded in inside-out patch under the conditions indicated; $\mathrm{Cs}^{+}$was in both bath and pipette, with $1 \mu \mathrm{M} \mathrm{Ca}{ }^{2+}$ in the bath; channel openings are plotted upward.

We also performed the complementary experiment to show that current activation by $\mathrm{Na}$ azide-induced $[\mathrm{ATP}]_{\mathrm{i}}$ depletion could be blocked by glibenclamide. As observed previously, when cells were studied using a whole-cell nystatin perforated-patch technique, exposure to $\mathrm{Na}$ azide $(1 \mathrm{mM})$ caused activation of the $\mathrm{NC}_{\text {Ca-ATP }}$ channel (Fig. 9Ca,b). Subsequent addition of $1 \mu \mathrm{M}$ glibenclamide caused full inhibition of the current that was turned on by $\mathrm{Na}$ azide (Fig. 9Cc). Together, these data suggest that sulfonylurea was acting on the same channel that was activated by $\mathrm{Na}$ azide-induced $[\mathrm{ATP}]_{\mathrm{i}}$ depletion and that sulfonylurea could block the channel after it had been opened by $[\text { ATP }]_{i}$ depletion.

\section{Tryptic digests}

Another characteristic feature of SUR-regulated $\mathrm{K}_{\mathrm{ATP}}$ function is that tryptic digestion of the cytoplasmic but not extracellular face of the channel causes loss of inhibition by sulfonylureas without altering sensitivity to ATP and without changing the biophysical properties of the channel (Proks and Ashcroft, 1993; Lee et al., 1994). We thus assessed the effect of trypsin on the cytoplasmic side of the $\mathrm{NC}_{\mathrm{Ca}-\mathrm{ATP}}$ channel. Experiments were performed using an inside-out patch configuration with $\mathrm{Cs}^{+}$on both sides of the membrane and $1 \mu \mathrm{M} \mathrm{Ca}^{2+}$ in the bath, which, as shown previously, produced robust channel activity (Fig. 10, first trace) that was strongly inhibited by $1 \mu \mathrm{M}$ glibenclamide (Fig. 10 , second trace). Subsequent washout of drug and exposure to $100 \mu \mathrm{g} / \mathrm{ml}$ trypsin for 3 min yielded a patch that still exhibited strong channel activity (Fig. 10, third trace) but was now completely unaffected by $1 \mu \mathrm{M}$ glibenclamide (Fig. 10, fourth trace); however, the biophysical properties of the channel, including open-channel conductance, open-channel times, and $\mathrm{Ca}^{2+}$-mediated activation, were unchanged, and the channel still maintained its typical sensitivity to ATP, showing reversible inhibition after addition of $1 \mathrm{~mm}$ ATP (Fig. 10, fifth and sixth traces). Similar observations were made in six patches. By contrast, exposure of the extracellular side to trypsin (four cells) had no effect on glibenclamide inhibition. These data on the $\mathrm{NC}_{\mathrm{Ca}-\mathrm{ATP}}$ channel paralleled exactly previous findings on $\mathrm{K}_{\mathrm{ATP}}$ channels, giving additional supporting evidence that SUR1 was involved in regulation of the $\mathrm{NC}_{\mathrm{Ca}-\mathrm{ATP}}$ channel. 
1

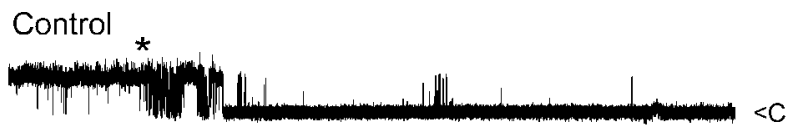

2

SUR1 Antibody

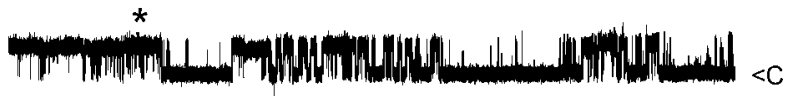

Control

3

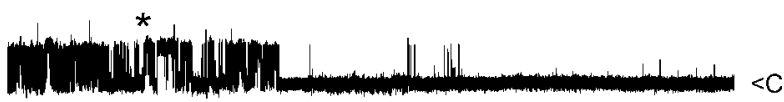

4

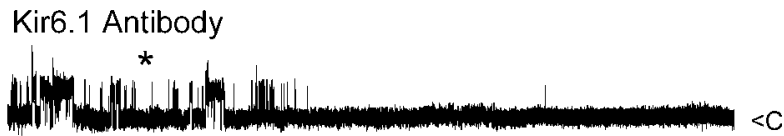

$5 \mathrm{pA} \mid 5 \mathrm{~s}$

Figure 11. Anti-SUR1 antibody but not anti-Kir6.1 antibody prevents glibenclamide block of $\mathrm{NC}_{\text {(a-ATP }}$ channel. Currents were recorded in inside-out patch, with $1 \mu \mathrm{m}$ glibenclamide added at asterisk; traces 1 and 2 are from the same patch before (1) and after (2) exposure to anti-SUR1 antibody; traces 3 and 4 are from a different patch before (3) and after (4) exposure to antiKir6.1 antibody; $\mathrm{Cs}^{+}$was in both bath and pipette, with $1 \mu \mathrm{m} \mathrm{Ca}{ }^{2+}$ in the bath; channel openings are plotted upward.

\section{Anti-SUR1 antibody}

To this point, all of our physiological and pharmacological data were consistent with the hypothesis that the pore-forming moiety of the $\mathrm{NC}_{\text {Ca-ATP }}$ channel was functionally regulated by SUR1. To further test this hypothesis, we studied the effect of anti-SUR1 antibody on glibenclamide inhibition of the channel. Experiments were performed using an inside-out patch configuration with $\mathrm{Cs}^{+}$on both sides of the membrane and $1 \mu \mathrm{M} \mathrm{Ca}^{2+}$ in the bath. As shown previously, channel activity was readily inhibited by addition of $1 \mu \mathrm{M}$ glibenclamide to the bath (Fig. 11, trace 1). Subsequent washout of glibenclamide and application of antiSUR1 antibody (final dilution, 1:1000; incubation time, $1 \mathrm{hr}$ at room temperature) resulted in a patch with channel activity that was no longer inhibited by $1 \mu \mathrm{M}$ glibenclamide (Fig. 11, trace 2). A similar finding was made in five patches from NR1A cells and in four patches from insulinoma cells (patches studied with $\mathrm{K}^{+}$as the charge carrier; data not shown). By contrast, application of anti-Kir6.1 antibody (final dilution, 1:1000; incubation time, $1 \mathrm{hr}$ at room temperature) was without effect on glibenclamide inhibition in three patches from NR1As (Fig. 11, traces 3 and 4), showing that the effect of anti-SUR1 antibody was specific.

\section{SUR-mediated cell swelling}

We reported previously that in freshly isolated NR1As, ATP depletion after exposure to $\mathrm{Na}$ azide caused cell blebbing and swelling that arose after activation of $\mathrm{NC}_{\mathrm{Ca}-\mathrm{ATP}}$ channels (Chen and Simard, 2001). Here we sought to determine whether SUR activators and sulfonylureas could be implicated in these pathological responses. As found previously, cells exhibited a stable morphological appearance when observed for $30 \mathrm{~min}$ or more with phase-contrast microscopy at room temperature (Fig. 12, control). After addition of $\mathrm{Na}$ azide $(1 \mathrm{~mm})$, cell blebbing typically became apparent after 7-10 min (Fig. 12, Na Azide). Opening of this channel by diazoxide $(100 \mu \mathrm{M})$ resulted in blebbing of the cells even without $[\mathrm{ATP}]_{\mathrm{i}}$ depletion (Fig. 12, Diazoxide); however, when cells were pretreated with glibenclamide $(1 \mu \mathrm{M})$, ad-
Control
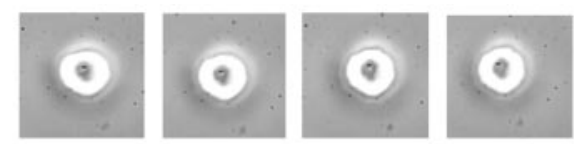

Na Azide
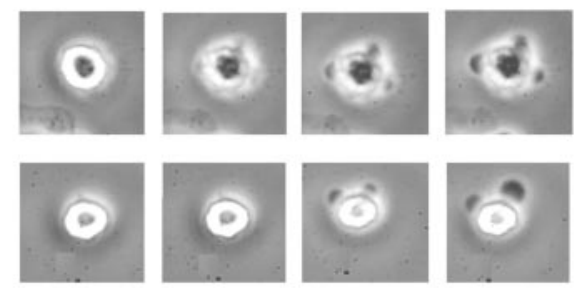

\section{$\mathrm{Na}$ Azide
+
Glibenclamide}
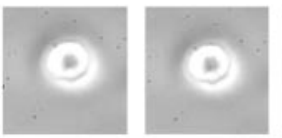

0
Diazoxide

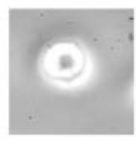

5

15

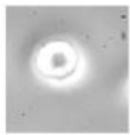

30 min
Figure 12. Cell blebbing of reactive astrocytes is caused by opening of $\mathrm{NC}_{\mathrm{Ca}-\mathrm{ATP}}$ channel. Each row of images was obtained with phase-contrast microscopy at $0-30$ min as indicated, from a control cell, a cell exposed to $1 \mathrm{~mm}$ Na azide, a cell exposed to $100 \mu \mathrm{m}$ diazoxide, and a cell exposed to $1 \mathrm{~mm}$ Na azide plus $1 \mu \mathrm{m}$ glibenclamide. All experiments were conducted at room temperature.

dition of $\mathrm{Na}$ azide did not result in any appreciable blebbing, even after 30 min or more of observation (Fig. 12, Na Azide + Glibenclamide). This finding accorded with previous observations that glibenclamide protected from opening of the $\mathrm{NC}_{\mathrm{Ca}-\mathrm{ATP}}$ channel after $[\mathrm{ATP}]_{\mathrm{i}}$ depletion (Fig. 9) and that opening of this channel preceded cell blebbing (Chen and Simard, 2001).

\section{Discussion}

The principal findings of this study are as follows: (1) the $\mathrm{NC}_{\text {Ca-ATP }}$ channel in NR1As was regulated by pharmacological and physiological mechanisms that mimicked exactly those described for SUR1 regulation of the $\mathrm{K}_{\mathrm{ATP}}$ channel in pancreatic $\beta$ cells; (2) glibenclamide-mediated block of the $\mathrm{NC}_{\mathrm{Ca}-\mathrm{ATP}}$ channel was prevented by anti-SUR1 antibody; and (3) NR1As exhibited specific sulfonylurea binding sites attributable to SUR1 but were not immunolabeled with anti-Kir6.1 or -Kir6.2 antibodies. The latter observations, coupled with the fact that our electrophysiological data were obtained using $\mathrm{Cs}^{+}$as the charge carrier, indicate that these cells do not possess $\mathrm{K}_{\mathrm{ATP}}$ channels. Rather, our data are consistent with the hypothesis that SUR1 regulates the $\mathrm{NC}_{\text {Ca-ATP }}$ channel in NR1As, and they suggest that this novel $\mathrm{NC}_{\text {Ca-ATP }}$ channel, like the $\mathrm{K}_{\mathrm{ATP}}$ channel in pancreatic $\beta$ cells, may be a heteromultimer composed of a channel moiety distinct from the SUR1 regulatory subunit.

Sulfonylurea agents act not only on various isoforms of SUR but also on other ABC family members, including CFTR and P-glycoprotein (Sheppard and Welsh, 1992; Schultz et al., 1996; Golstein et al., 1999); however, effects at these different sites are generally distinguishable by virtue of potency and mechanism of block. The sulfonylurea inhibitor glibenclamide is most potent at SUR1, with $\mathrm{EC}_{50}$ values of $\sim 2-30 \mathrm{~nm}$ (Yamazaki and Hume, 1997), compared with $\sim 150 \mathrm{nM}$ at SUR2A, and micromolar values at CFTR and P-glycoprotein. Another sulfonylurea, tolbutamide, is also highly effective at SUR1, with $\mathrm{EC}_{50}$ values of $\sim 5-30$ $\mu \mathrm{M}$ (Yamazaki and Hume, 1997), compared with $\sim 120 \mu \mathrm{M}$ at SUR2A, and higher values at CFTR and P-glycoprotein. Thus, the values observed here with the $\mathrm{NC}_{\mathrm{Ca}-\mathrm{ATP}}$ channel, $48 \mathrm{~nm}$ and 12 $\mu \mathrm{M}$ for glibenclamide and tolbutamide, respectively, accord well 
with the hypothesized involvement of SUR1 in regulation of the $\mathrm{NC}_{\text {Ca-ATP }}$ channel. Moreover, sulfonylurea inhibition of native pancreatic $\mathrm{K}_{\mathrm{ATP}}$ channels or of SUR1-Kir6.2 channels occurs via an allosteric mechanism that results in an increase in the closed dwell time of the channel, with no effect on the open-channel dwell time. Similarly, with the $\mathrm{NC}_{\text {Ca-ATP }}$ channel, sulfonylurea inhibition was characterized by an increase in closed dwell times with no change in the open dwell times. These effects on channel kinetics contrast with the open-channel blocking mechanism reported with sulfonylurea block of CFTR (Schultz et al., 1996; Venglarik et al., 1996). Thus, in terms of both potency and mechanism, sulfonylurea block of $\mathrm{NC}_{\text {Ca-ATP }}$ channels was indistinguishable from observations made with pancreatic $\mathrm{K}_{\mathrm{ATP}}$ and SUR1-Kir6.2 channels.

$\mathrm{K}_{\text {ATP }}$ channels in pancreatic $\beta$ cells are heteromultimers formed from Kir6.2 and the sulfonylurea receptor SUR1. Sensitivity to sulfonylureas, which is conferred by SUR1, is lost by exposure of the cytoplasmic but not the extracellular side to trypsin. Trypsin is believed to act on SUR1 itself, rather than on Kir6.2, because trypsin causes loss of sulfonylurea binding, whereas the biophysical properties of the channel itself are preserved. We thus reasoned that if similar findings could be made with the $\mathrm{NC}_{\mathrm{Ca}-\mathrm{ATP}}$ channel, this would further advance the hypothesis that SUR1 is linked to the $\mathrm{NC}_{\text {Ca-ATP }}$ channel. Indeed, we found that exposure of the cytoplasmic side of the $\mathrm{NC}_{\mathrm{Ca}-\mathrm{ATP}}$ channel to trypsin resulted in complete loss of sensitivity to glibenclamide, without altering channel opening, conductance, $\mathrm{Ca}^{2+}$-mediated activation, or sensitivity to block by ATP. Our findings with trypsin demonstrate that sulfonylurea sensitivity of the $\mathrm{NC}_{\mathrm{Ca}-\mathrm{ATP}}$ channel is conferred by a regulatory peptide moiety susceptible to tryptic cleavage and that this moiety is distinct from the ATP binding site and the channel pore, with the pore itself not being functionally altered by exposure to trypsin. These findings, which again mimic observations made on pancreatic $\mathrm{K}_{\mathrm{ATP}}$ channels, provide evidence linking trypsin-sensitive SUR and the $\mathrm{NC}_{\mathrm{Ca}-\mathrm{ATP}}$ channel.

Apart from conferring sensitivity to sulfonylurea inhibitors, SUR1 also confers sensitivity to $\mathrm{K}^{+}$channel openers (SUR activators). Notably, this diverse group of agents activates SURlinked channels but inhibits CFTR- and P-glycoprotein-linked channels (Sheppard and Welsh, 1992), making the SUR activators potentially more useful than sulfonylurea inhibitors as indicators of involvement of SUR. Moreover, these activators are essentially isoform specific in their effects, permitting provisional identification of SUR isoform (Babenko et al., 2000; Lawson, 2000). Diazoxide is highly effective at SUR1, with an $\mathrm{EC}_{50}$ value of $\sim 50 \mu \mathrm{M}$, and is essentially ineffective at SUR2, whereas pinacidil is highly effective at SUR2A, with an $\mathrm{EC}_{50}$ value of $\sim 10 \mu \mathrm{M}$, and is essentially ineffective at SUR1 (Fujita and Kurachi, 2000). Thus, our finding that $100 \mu \mathrm{M}$ diazoxide readily activated the $\mathrm{NC}_{\mathrm{Ca}-\mathrm{ATP}}$ channel, whereas pinacidil did not, strongly supports the hypothesis of involvement of SUR1 in regulation of the $\mathrm{NC}_{\text {Ca-ATP }}$ channel.

Overall, the pharmacological characteristics of the $\mathrm{NC}_{\mathrm{Ca}-\mathrm{ATP}}$ channel closely recapitulate the pharmacological profile of native pancreatic $\beta$-cell $\mathrm{K}_{\mathrm{ATP}}$ channels and of heterologously expressed Kir6.2-SUR1 channels. In addition, glibenclamide block of the channel was found to be prevented by application of anti-SUR1 antibody to the cytoplasmic side. The most parsimonious explanation for the constellation of findings reported here is that SUR1, identified at the protein and mRNA levels, functionally regulates the $\mathrm{NC}_{\mathrm{Ca}-\mathrm{ATP}}$ channel. This implies that the $\mathrm{NC}_{\mathrm{Ca}-\mathrm{ATP}}$ channel, like the $\mathrm{K}_{\mathrm{ATP}}$ channel, is a heteromultimer formed from
SUR1 regulatory subunits and molecularly distinct pore-forming subunits.

The identity of the putative pore-forming subunit of the $\mathrm{NC}_{\mathrm{Ca}-\mathrm{ATP}}$ channel remains to be determined; however, several features distinguish it from Kir6.x pore-forming subunits: (1) it is nearly equally permeable to $\mathrm{K}^{+}, \mathrm{Na}^{+}, \mathrm{Rb}^{+}, \mathrm{Li}^{+}$, and $\mathrm{Cs}^{+}$; (2) its conductance of $35 \mathrm{pS}$ is significantly less than the $\sim 80 \mathrm{pS}$ conductance of the $\mathrm{K}_{\mathrm{ATP}}$ channel; (3) it is regulated by intracellular $\mathrm{Ca}^{2+}$; and (4) it does not bind Kir6.1 or Kir6.2 antibodies. It seems unlikely that the pore-forming subunit of the $\mathrm{NC}_{\mathrm{Ca}-\mathrm{ATP}}$ channel would simply represent a post-translational modification of the Kir6.x subunit of a $\mathrm{K}_{\text {ATP }}$ channel, because this would imply a major modification of the selectivity filter and conductive pore and would require addition of a $\mathrm{Ca}^{2+}$ regulatory site. Full molecular characterization will require cloning of the poreforming subunit of the $\mathrm{NC}_{\text {Ca-ATP }}$ channel. Nevertheless, the data presented here favor the hypothesis that SUR1 regulates a novel pore-forming subunit. Thus, the $\mathrm{NC}_{\mathrm{Ca}-\mathrm{ATP}}$ channel becomes the first example of promiscuity of SUR1 outside of the Kir family of inward-rectifier $\mathrm{K}^{+}$-selective channels.

The normal physiological role of the $\mathrm{NC}_{\mathrm{Ca}-\mathrm{ATP}}$ channel remains to be determined, but some observations related to its function may be noted. Our imaging experiments showed that cells exhibiting glibenclamide binding were GFAP positive, indicating that they are reactive astrocytes, but that they comprised only a subpopulation of reactive astrocytes, being found most prominently in the gliotic capsule surrounding the foreign body sponge and to a lesser extent within the sponge itself, but not within the brain parenchyma, even in regions adjacent to the injury. Reactive astrocytes are found in abundance in adjacent brain (Perillan et al., 1999), but they do not exhibit glibenclamide binding. We reported previously that NRAs harvested from the gelatin sponge implant lose the $\mathrm{NC}_{\mathrm{Ca}-\mathrm{ATP}}$ channel when they are maintained in vitro under standard culture conditions (Chen and Simard, 2001), and we have since found that these cells retain expression of this channel when cultured under hypoxic conditions (our unpublished observation). Thus, we speculate that NR1A may be specifically adapted for hypoxic conditions within the gliotic capsule that are not found in adjacent areas of brain. The function of these cells encapsulating the sponge is unclear, but nonetheless it is evident that they have migrated to the sponge and that most $(>80 \%)$ of the cells present within the sponge, as identified by DAPI labeling, exhibit glibenclamide binding. Thus, there is the intriguing observation that migrating reactive astrocytes appear to express the $\mathrm{NC}_{\mathrm{Ca}-\mathrm{ATP}}$ channel only as they cross the border out of properly oxygenated parenchyma into the hypoxic region surrounding the foreign body. Because migrating glial cells are believed to have to shrink, to reduce their cell volume, to permit migration within the brain (Ransom et al., 2001), presumably the converse, i.e., swelling, would halt migration. Thus, migrating reactive astrocytes may use the $\mathrm{NC}_{\mathrm{Ca}-\mathrm{ATP}}$ channel to sense arrival in a hypoxic environment, opening the channel to initiate swelling and reverse the shrinkage imposed previously that allowed migration. Notably, in this process, these cells may well serve as a significant reservoir of water taken up from the extracellular space and stored intracellularly as "cytotoxic edema," a well known response to injury that can have deleterious effects on CNS function.

\section{References}

Aguilar-Bryan L, Nichols CG, Wechsler SW, Clement JP, Boyd III AE, Gonzalez G, Herrera-Sosa H, Nguy K, Bryan J, Nelson DA (1995) Cloning of the $\beta$ cell high-affinity sulfonylurea receptor: a regulator of insulin secretion. Science 268:423-426. 
Ammala C, Moorhouse A, Gribble F, Ashfield R, Proks P, Smith PA, Sakura H, Coles B, Ashcroft SJ, Ashcroft FM (1996) Promiscuous coupling between the sulphonylurea receptor and inwardly rectifying potassium channels. Nature 379:545-548.

Babenko AP, Aguilar-Bryan L, Bryan J (1998) A view of sur/KIR6. X, K channels. Annu Rev Physiol 60:667-687.

Babenko AP, Gonzalez G, Bryan J (1999) Two regions of sulfonylurea receptor specify the spontaneous bursting and ATP inhibition of $\mathrm{K}_{\mathrm{ATP}}$ channel isoforms. J Biol Chem 274:11587-11592.

Babenko AP, Gonzalez G, Bryan J (2000) Pharmaco-topology of sulfonylurea receptors. Separate domains of the regulatory subunits of $\mathrm{K}_{\mathrm{ATP}}$ channel isoforms are required for selective interaction with $\mathrm{K}^{+}$channel openers. J Biol Chem 275:717-720.

Bhat NM, Bieber MM, Teng NN (1990) One step separation of human fetal lymphocytes from nucleated red blood cells. J Immunol Methods 131:147-149.

Chen M, Simard JM (2001) Cell swelling and a nonselective cation channel regulated by internal $\mathrm{Ca}^{2+}$ and ATP in native reactive astrocytes from adult rat brain. J Neurosci 21:6512-6521.

Dalton S, Gerzanich V, Chen M, Dong Y, Shuba Y, Simard JM (2003) Chlorotoxin-sensitive $\mathrm{Ca}^{2+}$-activated $\mathrm{Cl}^{-}$channel in type $\mathrm{R} 2$ reactive astrocytes from adult brain. Glia 42:325-339.

Drain P, Li L, Wang J (1998) KATP channel inhibition by ATP requires distinct functional domains of the cytoplasmic $\mathrm{C}$ terminus of the poreforming subunit. Proc Natl Acad Sci USA 95:13953-13958.

Fujita A, Kurachi Y (2000) Molecular aspects of ATP-sensitive $\mathrm{K}^{+}$channels in the cardiovascular system and $\mathrm{K}^{+}$channel openers. Pharmacol Ther 85:39-53.

Gillis KD, Gee WM, Hammoud A, McDaniel ML, Falke LC, Misler S (1989) Effects of sulfonamides on a metabolite-regulated $\mathrm{ATP}_{\mathrm{i}}$-sensitive $\mathrm{K}^{+}$ channel in rat pancreatic $\beta$-cells. Am J Physiol 257:C1119-C1127.

Golstein PE, Boom A, van Geffel J, Jacobs P, Masereel B, Beauwens R (1999) P-glycoprotein inhibition by glibenclamide and related compounds. Pflügers Arch 437:652-660.

Harvey J, Hardy SC, Ashford ML (1999) Dual actions of the metabolic inhibitor, sodium azide on $\mathrm{K}_{\mathrm{ATP}}$ channel currents in the rat CRI-G1 insulinoma cell line. Br J Pharmacol 126:51-60.

Higgins CF (1992) ABC transporters: from microorganisms to man. Annu Rev Cell Biol 8:67-113.

Inagaki N, Gonoi T, Clement JP, Wang CZ, Aguilar-Bryan L, Bryan J, Seino S (1996) A family of sulfonylurea receptors determines the pharmacological properties of ATP-sensitive $\mathrm{K}^{+}$channels. Neuron 16:1011-1017.

Isomoto S, Kondo C, Yamada M, Matsumoto S, Higashiguchi O, Horio Y, Matsuzawa Y, Kurachi Y (1996) A novel sulfonylurea receptor forms with BIR (Kir6.2) a smooth muscle type ATP-sensitive $\mathrm{K}^{+}$channel. J Biol Chem 271:24321-24324.

Korn SJ, Marty A, Conner JA, Horn R (1991) Perforated patch recording. In: Methods in neuroscience. Electrophysiology and microinjection (Conn PM, ed), pp 364-373. San Diego: Academic.

Lawson K (2000) Potassium channel openers as potential therapeutic weapons in ion channel disease. Kidney Int 57:838-845.

Lee K, Ozanne SE, Rowe IC, Hales CN, Ashford ML (1994) The effects of trypsin on ATP-sensitive potassium channel properties and sulfonylurea receptors in the CRI-G1 insulin-secreting cell line. Mol Pharmaco 46:176-185.

Nichols CG, Shyng SL, Nestorowicz A, Glaser B, Clement JP, Gonzalez G Aguilar-Bryan L, Permutt MA, Bryan J (1996) Adenosine diphosphate as an intracellular regulator of insulin secretion. Science 272:1785-1787.

Panten U, Burgfeld J, Goerke F, Rennicke M, Schwanstecher M, Wallasch A, Zunkler BJ, Lenzen S (1989) Control of insulin secretion by sulfonylureas, meglitinide and diazoxide in relation to their binding to the sulfonylurea receptor in pancreatic islets. Biochem Pharmacol 38:1217-1229.

Perillan PR, Li X, Simard JM (1999) $\mathrm{K}^{+}$inward rectifier currents in reactive astrocytes from adult rat brain. Glia 27:213-225.

Perillan PR, Li X, Potts EA, Chen M, Bredt DS, Simard JM (2000) Inward rectifier $\mathrm{K}^{+}$channel Kir2.3 (IRK3) in reactive astrocytes from adult rat brain. Glia 31:181-192.

Proks P, Ashcroft FM (1993) Modification of K-ATP channels in pancreatic beta-cells by trypsin. Pflügers Arch 424:63-72.

Ransom CB, O’Neal JT, Sontheimer H (2001) Volume-activated chloride currents contribute to the resting conductance and invasive migration of human glioma cells. J Neurosci 21:7674-7683.

Ruknudin A, Schulze DH, Sullivan SK, Lederer WJ, Welling PA (1998) Novel subunit composition of a renal epithelial $\mathrm{K}_{\mathrm{ATP}}$ channel. J Biol Chem 273:14165-14171.

Schultz BD, DeRoos AD, Venglarik CJ, Singh AK, Frizzell RA, Bridges RJ (1996) Glibenclamide blockade of CFTR chloride channels. Am J Physio 271:L192-L200.

Sheppard DN, Welsh MJ (1992) Effect of ATP-sensitive $\mathrm{K}^{+}$channel regulators on cystic fibrosis transmembrane conductance regulator chloride currents. J Gen Physiol 100:573-591.

Shyng S, Ferrigni T, Nichols CG (1997a) Control of rectification and gating of cloned $\mathrm{K}_{\mathrm{ATP}}$ channels by the Kir6.2 subunit. J Gen Physiol 110:141-153.

Shyng S, Ferrigni T, Nichols CG (1997b) Regulation of $K_{\text {ATP }}$ channel activity by diazoxide and MgADP. Distinct functions of the two nucleotide binding folds of the sulfonylurea receptor. J Gen Physiol 110:643-654.

Sigworth FJ, Sine SM (1987) Data transformations for improved display and fitting of single-channel dwell time histograms. Biophys J 52:1047-1054.

Thomzig A, Wenzel M, Karschin C, Eaton MJ, Skatchkov SN, Karschin A, Veh RW (2001) Kir6.1 is the principal pore-forming subunit of astrocyte but not neuronal plasma membrane K-ATP channels. Mol Cell Neurosci 18:671-690.

Tucker SJ, Gribble FM, Zhao C, Trapp S, Ashcroft FM (1997) Truncation of Kir6.2 produces ATP-sensitive $\mathrm{K}^{+}$channels in the absence of the sulphonylurea receptor. Nature 387:179-183.

Tucker SJ, Gribble FM, Proks P, Trapp S, Ryder TJ, Haug T, Reimann F, Ashcroft FM (1998) Molecular determinants of KATP channel inhibition by ATP. EMBO J 17:3290-3296.

Venglarik CJ, Schultz BD, DeRoos AD, Singh AK, Bridges RJ (1996) Tolbutamide causes open channel blockade of cystic fibrosis transmembrane conductance regulator $\mathrm{Cl}^{-}$channels. Biophys J 70:2696-2703.

Yamazaki J, Hume JR (1997) Inhibitory effects of glibenclamide on cystic fibrosis transmembrane regulator, swelling-activated, and $\mathrm{Ca}^{2+}$. activated $\mathrm{Cl}^{-}$channels in mammalian cardiac myocytes. Circ Res 81:101109. 